\title{
Research on the Humor in Friends from the Perspective of Relevance Theory
}

\author{
Jie Wang \\ School of Foreign Studies, Xi' an University \\ Xi' an 710077, China \\ 13324564589@163.com
}

Keywords: Relevance theory; Humor; Cognitive principle; Friends

\begin{abstract}
Once after the publication of Relevance: Communication and Cognition (1986) by Sperber and Wilson, Great attention and interests have been aroused in linguistic field. More and more linguists have paid great attention to the relevance theory. In Relevance Theory, cognitive hypothesis and ostensive-inferential communication provide a reasonable explanation for the mechanism of humor generation; in the meantime, the intensity of humor effect comes from the contrast between maximal relevance and optimal relevance, as well as the degree of processing effort and cognitive effect. Firstly, this paper explains the mechanism of the humor generation from the perspective of cognition and communication. Secondly, it also analyzes the main influencing factors of the intensity of humorous. Thirdly, it also points out two significant things, the one is the contrast between the maximal relevance and optimal relevance, the other is the extra processing effort has a great impact on the intensity of humorous effect and endeavor to provide a theoretical basis for it. Apart from this, based on the classical humorous cases in the Friends, this paper gives a detail analysis with the purpose of providing a convinced method for humor study.
\end{abstract}

\section{Introduction}

Pragmatics mainly studies two core topics about the producing and comprehension of utterances. Many pragmatic theories have been used in explaining the generation of utterances, such as, presupposition, speech act theory by Austin, politeness principle, face theory and cooperative principle, etc. But, these theories don't give a determinate explanation about the mechanism of language. With the Relevance Theory by Sperber and Wilson appeared, it made up the above disadvantage'. RT made a determinate explanation about the mechanism of language. At the same time, RT found a new explaining method; About the language communication, RT gives a special and convincing explanation which defined language communication from language philosophy, cognitive psychology. RT is the first pragmatic theory to introduce cognitive linguistics into pragmatics, which is considered as the foundation of cognitive pragmatics. So, since the RT published, it made an effective explanation about every language phenomenon, so it used many fields involved in Pragmatics, discourse (Meng, 2001), language teaching and learning (Tang, 2002) and also translation (Gutt, 2000;Ran \& Zhang, 2007), literature(Yi, 2006), stylistics(Si, 2006), cognitive psychology, politeness(Ran, 2002), advertising(Yang, 2004), and humor(Yus,2003), etc. In terms of humor, the study about humor has a period of history, now, the mainly traditional humor theory had three: superiority theory, relief theory and incongruity theory, they tried to explain "how to generate", but they ignore the communicative intention of humor. But RT can make up this disadvantage. No matter the producing mechanism or communicative mechanism about humor, RT can make a reasonable explanation. But, the Relevance Theory about humor only appeared some journals, so, the study has huge space for development in this field. 


\section{Overview of Relevance Theory}

In the year of 1986, RT was put forward by Sperber and Wilson in the Communication and Cognition. It was thought as the base of cognitive pragmatics. As far as human's communication concerned, RT presented a reasonable explanation; what's more, it injected new vitality for the study of pragmatics.

Sperber and Wilson's Relevance Theory. Throughout the RT, relevance is thought of a common principle. Sperber and Wilson make a definition from three aspects involving context, an individual, a phenomenon. This paper will make a detailed depiction in the foundation of context, it will explain "what is the relevance". According to the Relevance Theory, relevance was defined "an assumption is relevant in a context if and only if it has some contextual effect in that context" (Sperber\&Wilson,2001:122 ). Precisely speaking, if it can achieve some contextual effects in the communication, we can say this tentative idea is relevant. such as:

\section{Are you thirsty?.}

I drank a Cup of Tea just now. In the above example, B didn't make an answer directly, so, if A wants to understand the intention of $\mathrm{B}, \mathrm{A}$ needs to infer and makes a series of environment language assumption. Obviously, A can infer that B isn't thirsty, so B needn't to drink water. According to the definition of relevance, the assumption of B isn't thirsty is pertinent in the context of language environment. But relevance isn't an exact value. For example, in the RT, it has the best relevance and the biggest relevance, the different degree of relevance is corresponded for them. In fact, the degree of relevance changes with the time goes by. The degree of relevance is different because of the effect and effort (Wilson, 1994). "An assumption is relevant in a context to the extent that the effort required to process it in this context is small" ("Sperber and Wilson, 1995"), this definition explains the relation between the effect, effort and the relevance perfectly.

Principles of Relevance. Just like the above definition of relevance, let us see the RT's mainly theory involved of Cognitive Principle and Communication Principle. These are two basic principles of relevance by Sperber and Wilson. According to the RT, first of all, communication is a cognitive process; As a cognitive mod finding relevance in the language communication, speaker and listeners can facilitate a successful communication. Secondly, communication is an inference process; speaker can produce an ostensive stimulus, the listener tries to guess the intention of the speaker. Putting the communication as the mainly concept of cognition process and inference process is involved of Cognitive Principle and Communication Principle which are known widely.

So, RT studies the language from the communication and cognition, which makes a new road for the cognitive study, and makes an important contribution in the language studying, what's more, getting the great progress.

\section{Relevance Theory and Humor}

Humor is an indispensable part in our everyday life; it can let us enjoy ourselves and helps us to improve interpersonal relationships. In recent years, humor has achieved more and more attention and is studied by people widely. The study theory about humor becomes more and more, moreover, it develops with a mature direction. In the linguistics, cooperative principle is widely used to explain humored work system.

Reviews on Humor. As we know, humor is an old and complex study object. In the western country, humor theory originated in Plato, and with the two thousand year's development, it got consummate and supplement gradually. In China, humor began with the paper by Lin Yutang in 1930 s, and goes into our everyday life, what's more, from then on, leads to a hot discussion domestically. In that way, first of all, what is the humor? From the ancient times to the present, many scholars have been trying to make a categorical definition, but it is not easy as we think. In the western country, different scholars have different definitions about humor. Humor originated the sense of superiority compared with others, it laughs at other people's shortcomings and mistakes. This idea obtained support by the superiority theory represented by Plato, Aristotle and Hobbes (McGhee, 1979). Kant thought the humor originated in the inconsistent between the expectations and reality (Attardo, 1997:396). However, Herbert Spencer and Freud insisted that human life is controlled by 
sex and attack from psychological analysis, but civilization and society standard restricted them. Only combined the knowledge with sex and attack, this chronic awareness was released, and then, the humor can generate (Hu, 2006). Therefore, they thought the humor originated from release. In China, in the Modern Chinese Dictionary, humor was defined an adjective and transliterated word, which means funny and meaningful. This word walked into China by Lin Yutang, "replace" you mo" with "English humor". Lin Yutang insisted that humor can't be comprehended as "joke" and "funny". When he tried to find Chinese traditional culture supported for humor. About humor, he has lots of ideas, at the same time, he didn't make a clear definition. In this paper, I will introduce a simple definition:

1. (The ability to understand and enjoy) what is funny and makes people laugh;

2. The ability of causing amusement

From Longman Dictionary (2004: 858)

In this paper, I divided humor into two categories: situational humor and verbal humor. This classification method was put forward by Henry Bergson at first. The main part of situational humor is body or action, situation and so on. At the same time, humorous speech is linguistic, text or the effect produced by verbal and text. So, we can find the difference between situational humor and verbal humor easily. In this paper, we will study humor from relevance theory, to a large extent, verbal humor is the main aspect which we want to study.

Relationship between Relevance and Humors Effect. "Sperber and Wilson's RT is not a theory specifically designed for the analysis of humor, but its theoretical hypotheses are suited to deal with how humorous interpretation are generated.(Yus, 2003)"

At first, from the communicative principle, language communication is an "ostensive-inferential" activity, so the comprehension about humor is an "ostensive-inferential" process, the speakers produce words as ostensive stimulus, and to obtain the communicative goal, speakers try to make their speaking interesting; Then, listeners try to infer the intention of speakers by a series of assumption, listeners can infer speaker's intention and immerse in communicative happiness. Based on "presumption of optimal relevance" by communicative principle, in the humor dialogue, the language is irrelevant or relevant a little, so the task of listeners is to find irrelevant or relevant a little dialogue to find the best relevant, and understand the humor of speakers in the speech.

Secondly, from the cognitive principle, the comprehension about humor is a cognitive and effort process. In the humor dialogue, to obtain the communicative goal, the speakers express their intention mildly and indirectly, so the listeners must pay more efforts to find the relevance than before. The importance of RT is that if you pay efforts to listen, you must identify the humor around the dialogue.

From the RT explanation about humor, the differences between the best relevance and the biggest relevance encourage the humor to produce. The following function model can describe the relation between humor and relevance clearly:
$\mathrm{H}=/ \mathrm{MR}-\mathrm{OR} / \mathrm{n}$
$(\mathrm{n}>0)$
(Qiu Xiping, 2011)

(H: Humor effect; MR: Maximal Relevance; OR: Optimal Relevance; n: constant

/MR-OR/: Difference between the maximal relevance and the optimal relevance)

From the above function model, we can find the effort of humor and relevance are direct ratio. In other words, if the difference between MR and OR is bigger, the humor effect is bigger.

\section{Interpretation of Humor in Friends from the Perspective of Relevance Theory}

Friends is a popular American situation comedy, it was firstly broadcasted in 1994, and it had lasted for 10 years. In this sitcom, it focuses on the daily life of six old friends who live in New York. Friends is one of the most popular situation comedy in western country, since it was first broadcasted, it had achieved the "Emmy Award Nominations" several times. Its success lies in the language of humor throughout the entire comedy. However, as far as the foreign language learners concerned, to understand every English language humor in this comedy is not an easy thing. In this paper, I elaborate the mechanism of the generation of humor based on the two principle of RT, combined with some examples from Friends. For these non-native English learners, it is helpful for them to understand the western humor. 
Relevance Theoretic Account of Mechanism of Humor Generation in Friends. According to $\mathrm{RT}$, communication is a recognition process. During the humor conversation, hearers construct a cognitive assumption under the cognitive circumstance, and then try to find the most relevant assumption, and promote the humor effect in the end. From RT, we can find in the cognitive circumstance, it mainly includes 3 information of logical information, encyclopedic information and lexical information. So, in this section, I will combine examples in Friends to introduce the lexical humor, encyclopedic humor, logical humor in detail.

Example 1: (Episode06, Season 10, from Friends)

Ross: Phoebe, what's wrong?

Phoebe: Oh, I'm just so exhausted from dragging around this... (She shows her ring) huge engagement ring!

In this conversation, when Ross seeing Phoebe tiredly went by and asked:" What's wrong?" According to cognitive principle, audience expects Phoebe's answer is relevant to Ross's question. However, out of everyone's expectation, Phoebe came up with a surprising answer. This surprising answer makes a conflict here. To solve this conflict, audiences need to reconstruct a new cognitive assumption under the cognitive circumstance. Combine the example above, the assumption audiences achieved before maybe is" Phoebe seems out of spirit because she is tired or unhappy", to achieve the effect of context, Phoebe answered Ross's question in an exaggerated way. In this conflict, audience should adjust their former cognitive assumption and reconstruct a new cognitive assumption to understand the intention of Phoebe's answer, and realize the humor effect finally.

Example 2 (Episode 05, Season 10, from Friends)

Rachel; Amy! Hi! Oh-oh-hoh!(They hug) Wow! You remember Joey?

Amy: Yeah! Hey, sure! The "Days of our Lives" guy!

Joey: That's right, yeah.

Amy: You're not good!

According the cognitive principle, when audiences attempt to realize the language humor, in this process and under the cognitive circumstance, the cognitive assumption will be produced. So, combine with the example above, in the context, the cognitive assumption of audiences expected is "to show appreciation to Joey". But on the contrary, the cognitive circumstance came up with Amy is "Joey is an actor, but he is not good". So what Amy had said makes a cognitive conflict in the conversation. Meanwhile, audiences will adjust and reconstruct a new cognitive assumption to find the optimal relevance, by this, the conflict will be solved with a reasonable interpretation. In this process, the humor effect can be achieved gradually.

Relevance Theoretic Account of Influencing Factors of Intensity of Humorous Effect in Friends. In this section, I will introduce two influencing factors of the intensity of humor effect: the first one is the contrast between maxim relevance and optimal relevance, to many linguist scholars, it is an important and meaningful research point; the other one is the processing effort and cognitive effect, they are two main influencing factors of the relevance.

According to the function model: (Qiu Xiping, 2011), the larger the contrast between maxim relevance and optimal relevance, the better intensity of humor effect can be achieved.

Example 3: (Episode 02, Season 01, from Friends)

Phoebe: Yeah. We don't speak. She's like this high-powered driven career type.

Chandler: What does she do?

Phoebe: She's a waitress.

According to RT, humans choose to find the relevance information from the humor utterance produced by the speaker. In this example, Phoebe and Chandler were talking about her twin sister. Obviously, we can find that she didn't like her sister at all, so when they were talking about her, Phoebe said her sister was like a "high-powered driven career type". From this sentence, audience can roughly infer the maxim relevance information "some high-status career". But the answer "waitress" broke the maxim relevance audience have formed, and the optimal relevance plays the role in the communication. When audience get the relevance assumption of "Phoebe disgust or scout her sister", 
the effect of humor is also been achieved. In this example, the contrary between maxim and optimal relevance has promoted the humor effect.

Example 4: (Episode 03, Season 07, from Friends)

Ross: Hey, Chandler, what are you doing tonight?

Chandler: Oh, why? Do you have a lecture?

Ross: No, why?

Chandler: Then, free as a bird. What's up?

Ross asked Chandler if he was available that night, because Ross's father wanted to invite him to play tennis together. According to RT, humans all want to pay the least effort to get the most cognitive effect. However, in the example 4, Chandler's question "Do you have a lecture" seemly had nothing to do with what Ross had asked. Based on the maxim relevance of humor, audience's expected answer might be "free or not". If Chandler choose "free or not" to answer Ross, the least cognitive effect will be achieved (that is to say having no humor effect or not humorous), because the audiences only pay a little cognitive effort. Surprisingly, Chandler asked Ross "Do you have a lecture"; maybe it was irrelevance to Ross's question. To understand this dialogue, audience need to pay extra processing effort to construct the optimal relevance "Chandler was so bored with Ross's lecture", so if Ross asked him to lesson to his lecture, he would answered him like this "I'm not available tonight". During this humor dialogue, cognitive effect the audiences can achieve will be promoted.

\section{Conclusion}

This paper studies the humor combine the conversation example in Friends in respective of RT. According to RT, all of human's communications with no exception comply with the relevance principle. As a form of language, humor has a great deal of pragmatic study value. From the definition of humor, this paper elaborates the relationship between humor and RT. Apart from this, based on the RT, the author also interprets the humor in Friends in detail. It is of great significance for the pragmatic study.

\section{References}

[1] ttardo, Salvatore and Victor, Raskin. Script Theory revised: Joke Similarity and Joke Representation Model. Humor: International Journal of Humor Research, 1991:293-347.

[2] Attardo, Salvatore. The Semantic Foundations of Cognitive Theories of Humor. Humor: International Journal of Humor Research, 1997:395-420.

[3] Blakemore, Diane. Semantic Constraints on Relevance. Oxford: Blackwell, 1987.

[4] Blakemore, Diane. Understanding Utterance: An Introduction to Pragmatics. Oxford: Blackwell, 1992.

[5] Blakemore, Diane. Relevance, Poetic Effects and Social Goals: A Reply to Culpeper. Language and Literature, 1994 (2): 49-_59.

[6] Blakemore, D. Understanding Utterances: An Introduction to Pragmatics. Oxford: Blackwell, 1992.

[7] Campbell, Joseph. An Applied Relevance Theory of the Making and Understanding of Rhetorical Arguments. Language and Communication,1992(4):45-55.

[8] Curco, Carmen. Relevance theory and humorous interpretations. University of Twente, 1996b:87-101.

[9] Curco, Carmen. The Pragmatics of Humorous Interpretations: A Relevance Theoretic Approach. UCL Department of Phonetics and Linguistics, London. 1997a. 
[10]Curco, Carmen. The Implicit Expression of Attitudes, Mutual Manifestenss, and Verbal Humor. UCL Working Papers in Linguistics, 1996. 